MAROUELLI, W.A.; SANT'ANA, R.R.; SILVA, W.L.C.; MORETTI, C.L.; VILELA, N.J. Avaliação técnica e econômica do espaçamento de gotejadores em tomateiro para processamento cultivado em fileiras simples e duplas. Horticultura Brasileira, Brasília, v. 21, n. 2, p. 202-206, abril/junho 2003.

\title{
Avaliação técnica e econômica do espaçamento de gotejadores em tomateiro para processamento cultivado em fileiras simples e duplas
}

\author{
Waldir A. Marouelli ${ }^{1}$; Rafael R. Sant'Ana ${ }^{2}$; Washington L. C. Silva ${ }^{1}$; Celso L. Moretti ${ }^{1}$;irlene J. Vilela ${ }^{1}$ \\ ${ }^{1}$ Embrapa Hortaliças, C. Postal 218, 70359-970 Brasília-DF; E.mail: waldir@cnph.embrapa.br. ${ }^{2}$ Unilever Bestfoods do Brasil Ltda., Rua \\ Arisco nº 01, 74665-320 Goiânia-GO
}

\section{RESUMO}

Avaliou-se o efeito de espaçamentos entre gotejadores $(10 \mathrm{~cm}$ e $30 \mathrm{~cm}$ ) e sistemas de plantio (fileiras simples e duplas, com uma linha de gotejo) sobre o rendimento físico e econômico e a qualidade de frutos de tomateiro para processamento, na região do Cerrado do Brasil. Um tratamento de controle, com plantio em fileiras simples, foi irrigado por aspersão. A produtividade comercial para o espaçamento de $10 \mathrm{~cm}$ foi $10 \%$ maior que para o de $30 \mathrm{~cm}$. O plantio em fileiras simples produziu $9 \%$ mais frutos do que o em fileiras duplas. A produtividade do tratamento por aspersão não diferiu do tratamento com gotejadores a $30 \mathrm{~cm}$ e fileiras duplas, mas foi pelo menos $15 \%$ menor do que nos demais tratamentos. A porcentagem de frutos podres não foi afetada pelo fator espaçamento entre gotejadores, mas foi maior no plantio em fileiras duplas. $\mathrm{Na}$ aspersão, a porcentagem de podres foi pelo menos $68 \%$ maior que nos tratamentos por gotejamento. Maior eficiência econômica foi obtida no tratamento com espaçamento entre gotejadores de $10 \mathrm{~cm}$ e plantio em fileiras simples $(12,7 \%)$, seguido do espaçamento de 10 $\mathrm{cm}$ e fileiras duplas $(7,5 \%)$. As taxas de retorno para estes tratamentos foram de 1,42 e 1,39 , respectivamente.

Palavras-chave: Lycopersicon esculentum, irrigação, gotejamento, espaçamento entre linhas, aspersão.

\begin{abstract}
Technical and economic evaluation of drip spacing for processing tomatoes under single- and double-row planting systems

Processing tomatoes crop response to drip spacing $(10 \mathrm{~cm}$ and $30 \mathrm{~cm}$ ) and planting systems (single- and double-row planting, and a lone drip line) was evaluated in Brasília, DF, Brazil. A control treatment with single-row planting system was sprinkle irrigated. Marketable yield for $10-\mathrm{cm}$ drip spacing was $10 \%$ higher than for $30 \mathrm{~cm}$. Yield from drip single-row treatments was $9 \%$ higher than from double-row ones. Yield from sprinkle irrigated plots did not differ from the 30 -cm drip spacing and double-row treatment, but was at least $15 \%$ lower than from other treatments. Rotten fruit rates were not affected by drip spacing factor, but were higher in doublerow treatments. In the control treatment, rotten fruit occurrence was at least $68 \%$ higher than in the drip treatments. Greater economic efficiency was obtained for the 10-cm drip spacing and single row system treatment $(12.7 \%)$, followed by drip spacing of $10 \mathrm{~cm}$ and double-row planting $(7.5 \%)$. The revenue rates for those treatments were 1.42 and 1.39 , respectively.
\end{abstract}

Keywords: Lycopersicon esculentum, irrigation, trickle, row spacing, sprinkle.

\section{(Recebido para publicação em 10 de abril de 2002 e aceito em 09 de abril de 2003)}

$\mathrm{O}$ tomateiro para processamento in dustrial é a hortaliça de maior importância econômica cultivada na região do Cerrado do Brasil. Em 2001, a área cultivada nos estados de Goiás e Minas Gerais foi de 12,7 mil hectares, o que representa cerca de $80 \%$ da área brasileira. A cultura é quase que totalmente irrigada por aspersão, sendo o pivô central e o plantio em fileiras simples o sistema de produção mais empregado na região (Giordano et al., 2000; Silva et al., 2001a).

Nos últimos anos, a utilização do pivô central vem sendo questionada pelo manejo inadequado da água de irrigação, pela falta de esquema eficiente de rotação de culturas, favorecendo, por exemplo, a ocorrência e o acúmulo de Sclerotinia sclerotiorum (Silva et al., 2001b), e pela necessidade de otimização do uso de água e energia. A ocorreência de bactérias, como
Xanthomonas campestris pv. e Pseudomonas syringae pv. tomato, favorecida pela irrigação por aspersão, também tem provocado perdas significativas na produção e na qualidade física e química dos frutos (Silva et al., 1999; Silva et al., 2001b).

Visando maximizar a produtividade e a qualidade de frutos, otimizar a eficiência do uso de água e energia, e minimizar o uso de agrotóxicos, alguns produtores começaram a utilizar, recentemente, o sistema de irrigação por gotejamento (Silva et al., 2001a). Para reduzir o investimento inicial, que pode atingir de duas a três vezes o custo do pivô central (Marouelli et al., 1998), a maioria dos usuários tem optado pelo plantio em fileiras duplas com o uso de apenas uma linha de gotejadores entre as duas linhas de plantas. Este sistema, no entanto, começou a ser utilizado no Brasil sem prévia avaliação de rendi- mento físico e econômico, muito embora seja utilizado para a irrigação do tomateiro para processamento em outros países (Colla et al., 1999; LowengartAycicege et al., 1999).

O espaçamento entre gotejadores é outro fator de grande importância para o sucesso da irrigação, o qual depende de situações como: espaçamento entre plantas, sensibilidade da cultura ao estresse hídrico, vazão do gotejador, tempo de irrigação e, principalmente, tipo de solo (Warrick, 1986; Burt \& Styles, 1994). Como regra geral, o espaçamento deve permitir a formação de uma faixa molhada contínua na superfície do solo, devendo ser igual a $80 \%$ do diâmetro do bulbo molhado (Keller $\&$ Bliesner, 1990). Para tomateiro cultivado em solos de cerrado não existem resultados de pesquisa sobre o espaçamento adequado entre gotejadores, sendo freqüentemente adotado 
pelos produtores espaçamentos entre 30 e $50 \mathrm{~cm}$, similarmente ao reportado por Lowengart-Aycicege et al. (1999) e Ashcroft (2001) para solos de Israel e Austrália, respectivamente. Burt \& Styles (1994), por outro lado, relatam que a maioria dos agricultores californianos utiliza espaçamento de 20 a $30 \mathrm{~cm}$ para cultivos em fileiras simples, e que espaçamentos ainda menores podem resultar em incremento de produtividade devido a melhor distribuição de água no solo.

Além disso, o espaçamento entre gotejadores, que pode afetar significativamente o custo do metro linear de alguns tubos gotejadores, praticamente não tem efeito sobre o custo daqueles com gotejadores de fluxo turbulento, tipo labirinto, moldados na parede do próprio tubo. $\mathrm{O}$ menor espaçamento entre gotejadores, no entanto, acarreta um incremento no custo do sistema devido a necessidade de se ter um maior número de setores por unidade de área, em razão da maior vazão por metro linear.

O objetivo do presente estudo foi avaliar, para as condições edafoclimáticas da região do cerrado do Brasil, o rendimento físico e econômico do tomateiro para processamento cultivado sob sistema de fileiras simples e duplas, com espaçamento entre gotejadores de 10 e $30 \mathrm{~cm}$.

\section{MATERIAL E MÉTODOS}

O experimento foi conduzido no campo experimental da Embrapa Hortaliças, em Brasília, DF, de maio a setembro de 2000, em um Latossolo Vermelho-Escuro distrófico, fase cerrado, textura argilosa e $1,2 \mathrm{~mm} \mathrm{~cm}^{-1}$ de capacidade de retenção de água.

Avaliou-se os fatores espaçamento entre gotejadores $(10$ e $30 \mathrm{~cm})$ e sistema de plantio (fileiras simples com uma linha lateral de gotejadores por fileira de plantas e fileiras duplas de plantas com uma lateral de gotejadores para cada fileira dupla de plantas), ou seja, os seguintes tratamentos: $10 \mathrm{~cm} /$ fileiras simples (T10S); $10 \mathrm{~cm} /$ fileiras duplas (T10D); $30 \mathrm{~cm} /$ fileiras simples (T30S); e $30 \mathrm{~cm} /$ fileiras duplas (T30D). Um tratamento irrigado por aspersão (TA), com sistema de plantio em fileiras simples, foi utilizado como controle.

As mudas do híbrido Heinz 9498 foram transplantadas no espaçamento de $120 \mathrm{~cm}$ x $30 \mathrm{~cm}$, no sistema de fileiras simples, e no espaçamento de $140 \mathrm{~cm} \mathrm{x}$ $40 \mathrm{~cm} \mathrm{x} 40 \mathrm{~cm}$, no sistema de fileiras duplas, em solo previamente irrigado até a capacidade de campo na camada até $40 \mathrm{~cm}$. As parcelas experimentais, localizadas dentro de uma área de plantio contínuo, foram de $28,8 \mathrm{~m}^{2}$ (4 fileiras de $6,0 \mathrm{~m}$ ) para o sistema de plantio em fileiras simples e de 32,4 $\mathrm{m}^{2}$ (3 fileiras duplas de 6,0 m) para o de fileiras duplas, tendo sido colhidos $4,5 \mathrm{~m}$ das linhas centrais de cada parcela.

A adubação total realizada, por hectare, foi de $120 \mathrm{~kg}$ de N, $200 \mathrm{~kg}$ de $\mathrm{K}_{2} \mathrm{O}$, $600 \mathrm{~kg}$ de $\mathrm{P}_{2} \mathrm{O}_{5}, 100 \mathrm{~kg}$ de $\mathrm{Ca}, 25 \mathrm{~kg}$ de $\mathrm{Mg}, 5 \mathrm{~kg}$ de $\mathrm{Zn}$ e $2 \mathrm{~kg}$ de B. Nos tratamentos por gotejamento, $85 \%$ do $\mathrm{Ne}$ do $\mathrm{K}$ e $30 \%$ do Ca foram aplicados semanalmente via fertirrigação. No tratamento por aspersão, $65 \%$ do N, $40 \%$ do $\mathrm{K}$ e $30 \%$ do Ca foram aplicados em cobertura aos 25 dias e 50 dias após o transplante. Os demais nutrientes e o restante do $\mathrm{N}$, do $\mathrm{K}$ e do $\mathrm{Ca}$ foram fornecidos em pré-plantio.

Foram utilizados tubos gotejadores com vazão de $1,2 \mathrm{~L} \mathrm{~h}^{-1}$ por emissor. Para minimizar danos mecânicos e, principalmente por roedores, as laterais foram enterradas entre 3 e $5 \mathrm{~cm}$ de profundidade. A freqüência de irrigação e a lâmina de água aplicada foram iguais para todos os tratamentos por gotejamento. O turno de rega variou de 1 a 2 dias durante os primeiros 10 dias após o transplante, de 3 a 4 dias até o início da frutificação, de 2 dias na fase de desenvolvimento de frutos e de 3 a 4 dias após $10 \%$ dos frutos estarem maduros (Marouelli \& Silva, 2000). A lâmina de água aplicada foi computada conforme Keller \& Bliesner (1990), a partir da evaporação do tanque Classe A, coeficientes de cultura reportados por Allen et al. (1998) e fração de área sombreada pelas plantas.

As irrigações no tratamento TA foram realizadas por microaspersores setoriais, com intensidade de aplicação de $49 \mathrm{~mm} \mathrm{~h}^{-1}$. O manejo de água foi realizado segundo Marouelli \& Silva (2000), a partir da evaporação de um tanque Clas- se A instalado a $500 \mathrm{~m}$ do local do experimento, de forma a maximizar a produtividade do tomateiro.

O monitoramento da tensão de água no do solo foi realizado por tensiômetros instalados a $10 \mathrm{~cm}$ da planta/gotejador (Lowengart-Aycicege et al., 1999) e a $50 \%$ da profundidade efetiva do sistema radicular, ou seja, a $10 \mathrm{~cm}$ de profundidade no estádio vegetativo (1 a 30 dias após o transplante), a $15 \mathrm{~cm}$ no início da frutificação (31 a 55 dias) e a 20 $\mathrm{cm}$ a partir daí (56 a 116 dias). A tensão de água do solo no tratamento por aspersão, ao longo do estádio vegetativo, foi estimada indiretamente a partir da medição da umidade do solo pelo método das pesagens (Bernardo, 1995).

Foram avaliadas as variáveis: estande final, massa da parte aérea, seca a $60^{\circ} \mathrm{C}$ (exceto os frutos), produtividade comercial, massa média de fruto comercial, número de frutos por planta, frutos podres e verdes, sólidos solúveis totais e eficiência de uso de água, em quilogramas de frutos comerciais por metro cúbico de água total aplicada por irrigação.

Para análise de variância dos dados utilizou-se delineamento de blocos ao acaso, em esquema fatorial 2 x 2, com seis repetições. Para comparação das médias do tratamento de controle por aspersão contra as médias dos tratamentos por gotejamento empregou-se o teste "t" de comparação múltipla de Dunnett.

A análise econômica foi realizada por meio dos indicadores econômicos: (a) receita líquida, dada pela diferença entre a receita total e o custo total anual (fixo e variável); (b) taxa de retorno econômico, dada pela relação entre a receita total e o custo total anual; (c) tempo de recuperação do investimento ("payback" simples), dado pela relação entre o valor de aquisição do sistema de irrigação e o fluxo de caixa anual; (d) coeficiente de eficiência econômica, dado pela relação entre o incremento de receita líquida, proporcionado pelo uso do gotejamento comparativamente à aspersão, e o respectivo custo total anual do gotejamento; (e) vantagem relativa, dada pela relação entre o incremento de receita líquida, proporcionado pelo uso do gotejamento comparativamente à 
aspersão, e a receita líquida da aspersão. O procedimento de análise adotado é descrito detalhadamente em Marouelli \& Silva (1998).

$\mathrm{O}$ investimento inicial para aquisição dos sistemas de irrigação por gotejamento, excetuando-se os tubos gotejadores, foi de: $\mathrm{R} \$ 3.900,00 \mathrm{ha}^{-1}$ para o tratamento T10S; R \$3.800,00 ha ${ }^{-1}$ para o T10D; R\$ 3.100,00 ha-1 para o T30S; e R\$ 3.000,00 ha-1 para o T30D. O custo dos tubos gotejadores, com emissores de fluxo turbulento, do tipo labirinto incorporado, e espessura de parede de $200 \mathrm{~mm}$, foi de $\mathrm{R} \$ 1.400,00 \mathrm{ha}^{-1}$ para o sistema de fileiras duplas e de $\mathrm{R} \$$ 2.100,00 ha-1 para o de fileiras simples, independente do espaçamento entre gotejadores. O investimento considerado para o tratamento TA foi $\mathrm{R} \$ 2.400,00$ $\mathrm{ha}^{-1}$, que representa o custo de um pivô central de 70 ha, o sistema mais utilizado para tomate.

O custo fixo anual do sistema de irrigação foi igual a depreciação média, computada de forma linear simples, mais a remuneração do capital investido, computada pelo produto entre a taxa de juro de $6 \%$ ao ano, paga pela caderneta de poupança, e a média entre o valor do investimento e o de sucata.

$\mathrm{O}$ custo de produção, excluindo os custos fixos e variáveis da irrigação, e os custos de colheita e transporte, foi de $\mathrm{R} \$ 2.900,00 \mathrm{ha}^{-1}$ para os tratamentos por gotejamento e de R \$3.300,00 ha-1 para o por aspersão. $O$ custo de mão-de-obra para irrigação foi de $\mathrm{R} \$ 4,50 \mathrm{~h}$-homem ${ }^{-1}$, de $\mathrm{R} \$ 12,00 \mathrm{t}^{-1}$ para colheita manual, de $\mathrm{R} \$ 15,00 \mathrm{t}^{-1}$ para transporte da produção e de $\mathrm{R} \$ 0,07 \mathrm{kWh}^{-1}$ para energia elétrica. $\mathrm{O}$ preço médio do produto pago ao agricultor foi de $\mathrm{R} \$ 85,00 \mathrm{t}^{-1}$.

Outros índices adicionais utilizados na análise econômica foram: (a) vida útil de 10 anos para o sistema de gotejamento, 3 anos para o tubo gotejador e 15 anos para o pivô central; (b) uso de energia de $0,20 \mathrm{kWh} \mathrm{m}^{-3}$ de água para o gotejamento e $0,40 \mathrm{kWh} \mathrm{m}^{-3}$ de água para o pivô central; (c) uso de mão-de-obra por irrigação de $0,3 \mathrm{~h} \mathrm{ha}^{-1}$ para o gotejamento e de $0,2 \mathrm{~h} \mathrm{ha}^{-1}$ para o pivô central; (d) custo de manutenção de $2 \%$ (do investimento inicial) para o sistema de gotejamento, $7 \%$ para o tubo gotejador e $5 \%$ para o pivô central. $\mathrm{O}$ valor de sucata, computado em função do valor inicial do equipamento, foi de $5 \%$ para o sistema de gotejamento, $1 \%$ para o tubo gotejador e $10 \%$ para o pivô central (Marouelli \& Silva, 1998).

Os custos e valores financeiros utilizados são referentes a safra de 2001, tendo sido obtidos junto às indústrias de processamento, empresas de equipamentos de irrigação e produtores. $\mathrm{Na}$ análise somente foi considerado um cultivo de tomate a cada ano; assim, um ano foi igual a uma safra de tomate.

\section{RESULTADOS E DISCUSSÃO}

A lâmina total de irrigação aplicada foi de $370 \mathrm{~mm}$ (50 irrigações) nos tratamentos irrigados por gotejamento e de $430 \mathrm{~mm}$ (28 irrigações) no tratamento irrigado por aspersão. $\mathrm{O}$ menor uso de água no gotejamento, muito embora as irrigações tenham sido realizadas em regime de mais alta freqüência que na aspersão, deve-se, principalmente, à menor evaporação de água, em função do sistema não molhar toda a superfície do solo, e à maior eficiência de aplicação de água do sistema por gotejamento (Keller \& Bliesner, 1990), estimada, a nível de experimento, em $93 \%$ contra $85 \%$ do sistema por aspersão. Ocorreram chuvas (149 mm) somente durante os últimos 15 dias que antecederam a colheita do tomateiro.

Embora o manejo da água de irrigação tenha sido igual para todos os tratamentos irrigados por gotejamento, houve variação na tensão máxima de água no solo a que as plantas foram submetidas. A tensão avaliada a $50 \%$ da profundidade efetiva das raízes $(10 \mathrm{~cm}$ no estádio vegetativo; $15 \mathrm{~cm}$ no início da frutificação; $20 \mathrm{~cm}$ a partir daí) e a 10 $\mathrm{cm}$ da planta/gotejador foi em média de $20 \mathrm{kPa}$ para o tratamento T10S, de 25 kPa para os tratamentos T10D e T30S, e de $30 \mathrm{kPa}$ para o T30D. A tensão no tratamento TA foi de $140 \mathrm{kPa}$ no estádio vegetativo e de $35 \mathrm{kPa}$ no estádio reprodutivo.

Não houve interação significativa $(p>0,05)$ entre os fatores sistema de plantio e espaçamento entre gotejadores para nenhuma das variáveis estudadas. A massa seca da parte aérea (média de 2,50 $\mathrm{t} \mathrm{ha}^{-1}$ ), a con- centração de maturação de frutos na colheita $(96,2 \%$ em massa) e o estande final (média de 27.068 plantas ha $^{-1}$ ) não foram afetados significativamente pelos tratamentos. Prieto et al. (1999) e Marouelli \& Silva (2002) também observaram que o sistema de irrigação utilizado não afetou a produção de biomassa e a taxa de maturação de frutos de tomate. A colheita de todas as parcelas foi realizada aos 116 dias após o transplante de mudas.

O número de frutos comerciais por unidade de área (média de 154 frutos $\mathrm{m}^{-2}$ ) e a massa de fruto comercial (média de $80,7 \mathrm{~g}$ ) não foram afetadas por nenhum dos fatores estudados. Pelo teste de Dunnett, verificou-se que: (a) o número de frutos por unidade de área no tratamento TA (136 frutos $\mathrm{m}^{-2}$ ) foi menor que no tratamento T10S (166 frutos $\mathrm{m}^{-2}$ ), não diferindo dos demais tratamentos; (b) a massa de fruto comercial no tratamento TA não diferiu dos tratamentos irrigados por gotejamento. Da mesma forma, Prieto et al. (1999) verificaram que plantas de tomateiro irrigadas por gotejamento e por aspersão produziram frutos de tamanho similar.

A produtividade comercial obtida no espaçamento entre gotejadores de 10 $\mathrm{cm}$ foi em média $10,0 \%$ maior que no espaçamento de $30 \mathrm{~cm}$, enquanto no sistema de fileiras simples foi $9,1 \%$ maior que no sistema de fileiras duplas (Tabela 1). O incremento de produtividade foi devido, provavelmente, ao fornecimento mais uniforme de água junto ao sistema radicular das plantas (Burt \& Styles, 1994).

Muito embora o número de frutos por unidade de área não tenha sido afetado estatisticamente pelos tratamentos por gotejamento, esta variável foi a responsável pelo incremento de produtividade observado, haja visto existir, pelo teste de Pearson, correlação significativa $(\mathrm{p}<0,01)$ da produtividade com o número de frutos, mas não com a massa de fruto ou o estande final de plantas. A produtividade obtida no tratamento TA (106,8 $\left.\mathrm{t} \mathrm{ha}^{-1}\right)$ não diferiu estatisticamente da observada no tratamento T30D, mas, devido a redução do número de frutos por unidade de 
área, foi $12,7 \%$ a $22,2 \%$ menor que as observadas nos tratamentos T10S, T10D e T30S (Tabela 1).

A porcentagem de frutos podres não foi influenciada pelo fator espaçamento entre gotejadores, mas foi maior nos tratamentos com sistema de plantio em fileiras duplas (Tabela 2). O menor apodrecimento de frutos deve-se, provavelmente, ao maior arejamento no dossel proporcionado no sistema em fileiras simples. Como a massa da parte aérea, nos dois sistemas de plantio, foi estatisticamente igual e a fração de cobertura do solo pelas plantas no sistema em fileiras duplas $(0,75$ no início da maturação) menor que no sistema em fileiras simples $(0,90$ no início da maturação), houve um maior adensamento vegetal entre as duas fileiras de plantas, no sistema em fileiras duplas, o que certamente pode ter favorecido uma maior incidência de doenças. A incidência de frutos podres no tratamento TA $(18,1 \%)$ foi pelo menos $68 \%$ maior que em qualquer tratamento irrigado por gotejamento, devido à maior incidência de doenças favorecidas pelo molhamento do dossel vegetativo pela aspersão (Silva et al., 1999).

A eficiência do uso de água (EA) foi afetada tanto pelo fator sistema de plantio quanto pelo fator espaçamento entre gotejadores. O maior valor de EA foi obtido para o sistema de fileiras simples e espaçamento de $10 \mathrm{~cm}$ entre gotejadores (Tabela 3). A EA no tratamento TA $\left(24,9 \mathrm{~kg} \mathrm{~m}^{-3}\right)$ foi significativamente menor, pelo teste de Dunnett, que nos tratamentos irrigados por gotejamento. $\mathrm{O}$ incremento médio de $35 \%$ na EA no gotejamento, comparativamente a aspersão, é semelhante ao relatado por Prieto et al. (1999) e Marouelli \& Silva (2002).

O teor de sólidos solúveis totais (média de $4,1 \%$ ) não foi afetado pelos tratamentos, provavelmente pelas seguintes razões: (a) as tensões máximas de água no solo a que as plantas foram submetidas, ao longo do estádio reprodutivo, foram relativamente próximas em todos os tratamentos (20 a 35 $\mathrm{kPa}$ ); (b) a ocorrência de chuvas duran-

Tabela 1. Produtividade comercial de frutos de tomate para processamento $\left(\mathrm{t} \mathrm{ha}^{-1}\right)$ para os tratamentos irrigados por gotejamento. Brasília, Embrapa Hortaliças, 2000.

\begin{tabular}{cccc}
\hline \multirow{2}{*}{$\begin{array}{c}\text { Espaçamento } \\
\text { entre }\end{array}$} & \multicolumn{2}{c}{ Sistema de plantio } & \multirow{2}{*}{ Média } \\
\cline { 2 - 3 } gotejadores & Fileiras simples & Fileiras duplas & \\
\hline $10 \mathrm{~cm}$ & 137,2 & 123,5 & $130,4 \mathrm{~A}$ \\
$30 \mathrm{~cm}$ & 122,4 & 114,5 & $118,5 \mathrm{~B}$ \\
\hline Média & $129,8 \mathrm{a}$ & $119,0 \mathrm{~b}$ & \\
\hline
\end{tabular}

Obs.: As médias seguidas por letras diferentes diferiram entre si pelo teste $\mathrm{F}(\mathrm{p}<0,01)$.

Tabela 2. Porcentagem de frutos podres de tomate para processamento para os tratamentos irrigados por gotejamento. Brasília, Embrapa Hortaliças, 2000.

\begin{tabular}{cccc}
\hline \multirow{2}{*}{$\begin{array}{c}\text { Espaçamento } \\
\text { entre }\end{array}$} & \multicolumn{2}{c}{ Sistema de plantio } & \multirow{2}{*}{ Média } \\
\cline { 2 - 3 } gotejadores & Fileiras simples & Fileiras duplas & \\
\hline $10 \mathrm{~cm}$ & 7,3 & 10,8 & $9,1 \mathrm{~A}$ \\
$30 \mathrm{~cm}$ & 6,6 & 9,2 & $7,9 \mathrm{~A}$ \\
\hline Média & $7,0 \mathrm{~b}$ & $10,0 \mathrm{a}$ & \\
\hline
\end{tabular}

Obs.: As médias seguidas por letras diferentes diferiram entre si pelo teste $\mathrm{F}(\mathrm{p}<0,01)$.

Tabela 3. Eficiência do uso de água do tomateiro para processamento $\left(\mathrm{kg} \mathrm{m}^{-3}\right)$ para os tratamentos irrigados por gotejamento. Brasília, Embrapa Hortaliças, 2000.

\begin{tabular}{cccc}
\hline \multirow{2}{*}{$\begin{array}{c}\text { Espaçamento } \\
\text { entre }\end{array}$} & \multicolumn{2}{c}{ Sistema de plantio } & \multirow{2}{*}{ Média } \\
\cline { 2 - 3 } gotejadores & Fileiras simples & Fileiras duplas & \\
\hline $10 \mathrm{~cm}$ & 37,1 & 33,4 & $35,3 \mathrm{~A}$ \\
$30 \mathrm{~cm}$ & 33,1 & 31,0 & $32,0 \mathrm{~B}$ \\
\hline Média & $35,1 \mathrm{a}$ & $32,2 \mathrm{~b}$ & \\
\hline
\end{tabular}

Obs.: As médias seguidas por letras diferentes diferiram entre si pelo teste $\mathrm{F}(\mathrm{p}<0,01)$.

te as últimas duas semanas que antecederam a colheita dos frutos (LowengartAycicege et al., 1999; Cahn et al., 2001).

Os indicadores econômicos para os diferentes tratamentos, incluindo o custo total anual, a receita total, a receita líquida, a taxa de retorno econômico e o tempo de recuperação do investimento, assim como, a eficiência econômica e a vantagem relativa dos tratamentos por gotejamento, relativamente ao tratamento por aspersão, são apresentados na Tabela 4. O tratamento T10S foi o que apresentou maior eficiência econômica $(12,7 \%)$ e vantagem relativa $(43,4 \%)$, comparativamente à tecnologia tradicional de irrigação por aspersão (TA), seguindo do T10D. Para os tratamentos em destaque, T10S e $\mathrm{T} 10 \mathrm{D}$, as taxas de retorno foram de 1,42 e 1,39 e as receitas líquidas de $\mathrm{R} \$ 3.450,37$ e $2.971,63 \mathrm{ha}^{-1}$ ano $^{-1}$, respectivamente. O tempo de recuperação do investimento foi menor no tratamento TA (1,0 ano) e maior no T30S (1,9 anos), enquanto nos demais tratamentos o tempo de retorno foi de 1,7 anos. Com base nos indicadores econômicos obtidos, conclui-se que o tratamento T10S destacou-se, dentre os demais, como o de melhor desempenho técnico e econômico, seguido do T10D, T30S, T30D e TA.

$\mathrm{O}$ sistema de plantio em fileiras duplas e tubos gotejadores com maior espaçamento entre emissores (TD30), que é o mais utilizado pelos produtores de tomate que irrigam por gotejamento, foi o que apresentou desempenho físico e econômico menos favorável dentre os sistemas por gotejamento avaliados. 
Tabela 4. Indicadores econômicos do tomateiro para processamento para os tratamentos irrigados por gotejamento e por aspersão. Brasília, Embrapa Hortaliças, 2001.

\begin{tabular}{|c|c|c|c|c|c|}
\hline \multirow{3}{*}{ Indicador econômico } & \multirow{3}{*}{ Aspersão } & \multicolumn{4}{|c|}{ Gotejamento } \\
\hline & & \multicolumn{2}{|c|}{ Fileiras duplas } & \multicolumn{2}{|c|}{ Fileiras simples } \\
\hline & & $30 \mathrm{~cm}$ & $10 \mathrm{~cm}$ & $30 \mathrm{~cm}$ & $10 \mathrm{~cm}$ \\
\hline Custo total $\left(\mathrm{R} \$\right.$ ha $\left.^{-1} \mathrm{ano}^{-1}\right)$ & $6.672,40$ & $7.165,67$ & $7.525,87$ & $7.694,83$ & $8.211,63$ \\
\hline Receita total $\left(\mathrm{R} \$\right.$ ha $^{-1}$ ano $\left.^{-1}\right)$ & $9.078,00$ & $9.732,50$ & $10.497,50$ & $10.404,00$ & $11.662,00$ \\
\hline Receita líquida $\left(\mathrm{R} \$\right.$ ha $^{-1}$ ano $\left.^{-1}\right)$ & $2.405,60$ & $2.566,83$ & $2.971,63$ & $2.709,17$ & $3.450,37$ \\
\hline Taxa de retorno simples (fração) & 1,36 & 1,36 & 1,39 & 1,35 & 1,42 \\
\hline Tempo de retorno (ano) & 1,0 & 1,7 & 1,7 & 1,9 & 1,7 \\
\hline Eficiência econômica* (\%) & -- & 2,3 & 7,5 & 3,9 & 12,7 \\
\hline Vantagem relativa* $(\%)$ & -- & 6,7 & 23,5 & 12,6 & 43,4 \\
\hline
\end{tabular}

* Relativo à tecnologia tradicional de irrigação por aspersão.

\section{AGRADECIMENTOS}

À Rain Bird do Brasil Ltda. pela doação de parte dos sistemas de irrigação e à Unilever BestFoods do Brasil Ltda. pelo fornecimento das mudas de tomateiro.

\section{LITERATURA CITADA}

ALLEN, R.G.; PEREIRA, L.S.; RAES, D.; SMITH, M. Crop evapotranspiration: guidelines for computing crop water requirements. Roma: FAO, 1998. 328 p. (Irrigation and Drainage Papers, 56).

ASHCROFT, W.J. Drip irrigation of processing tomatoes in Australia. Acta Horticulturae, v. 542, p. 97-99, 2001.

BERNARDO, S. Manual de irrigação. 6.ed. Viçosa: UFV, $1995.657 \mathrm{p}$

BURT, C.M.; STYLES, S.W. Drip and microirrigation for trees, vines, and row crops. San Luis Obispo: Irrigation Training and Research Center/California Polytechnic State University, 1994. $261 \mathrm{p}$.

CAHN, M.D.; HERRERO, E.V.; SNYDER, R.L.; HANSON, B.R. Water management strategies for improving fruit quality of drip-irrigated processing tomatoes. Acta Horticulturae, v. 542, p. 111-116, 2001.
COLLA, G.; CASA, R.; LOCASCIO, B.; SACCARDO, F.; TEMPERINI, O.; LEONI, C. Responses of processing tomato to water regime and fertilization in Central Italy. Acta Horticulturae, v. 487, p. 531-535, 1999.

GIORDANO, L.B.; SILVA, J.B.C.; BARBOSA, V. Escolha de cultivares e plantio. In: SILVA, J.B.C.; GIORDANO, L.B. Tomate para processamento industrial. Brasília: Embrapa, 2000. p. 36-59.

KELLER, J.; BLIESNER, R.D. Sprinkler and trickle irrigation. New York: VanNostrand Reinhold, 1990. $652 \mathrm{p}$.

LOWENGART-AYCICEGI, A.; MANOR, H.; KRIEGER, R.; GERA, G. Effects of irrigation scheduling on drip-irrigated processing tomatoes. Acta Horticulturae, v. 487, p. 513-518, 1999.

MAROUELLI, W.A.; SILVA, W.L. C. Irrigação. In: SILVA, J.B.C.; GIORDANO, L.B. Tomate para processamento industrial. Brasília: Embrapa, 2000. p. 60-71.

MAROUELLI, W.A.; SILVA, W.L.C. Profundidade de instalação da linha de gotejadores em tomateiro para processamento industrial. Horticultura Brasileira, v. 20, n. 2, p. 206-210, 2002.

MAROUELLI, W.A.; SILVA, W.L.C. Seleção de sistemas de irrigação para hortaliças. Brasília: EMBRAPA-CNPH, 1998. 15 p. (Circular Técnica da Embrapa Hortaliças, 11).
MAROUELLI, W.A.; SILVA, W.L.C.; SILVA, H.R. Seleção de sistemas de irrigação para o cultivo de tomateiro industrial. In: CONGRESSO BRASILEIRO DE ENGENHARIA AGRÍCOLA, 27., 1998, Poços de Caldas. Anais... Poços de Caldas: SBEA-UFLA, 1998. v. 2, p. 67-69.

PRIETO, M.H.; LÓPEZ, J.; BALLESTEROS, R. Influence of irrigation system and strategy of the agronomic and quality parameters of the processing tomatoes in Extremadura. Acta Horticulturae, v. 487, p. 575-579, 1999.

SILVA, W.L.C.; GIORDANO, L.B.; MAROUELLI, W.A.; FONTES, R.R.; GORNAT, B. Response of six processing tomatoes cultivars to subsurface drip fertigation. Acta Horticulturae, n. 487, p. 569-573, 1999.

SILVA, W.L.C.; GIORDANO, L.B.; SILVA, J.B.C.; MAROUELLI, W.A. The use of drip irrigation for processing tomatoes in Brazil. Acta Horticulturae, v. 542, p. 103-105, 2001 a.

SILVA, W.L.C.; PEREIRA, W.; LOPES, C.A.; FONTES, R.R.; LOBO JÚNIOR., M. Weeds and plant diseases in crop rotation systems for processing tomatoes under center pivot in Central Brazil. Acta Horticulturae, n. 542, p. 297-302, 2001b.

WARRICK, A.W. Design principles: soil water distribution. In: NAKAYAMA, F.S.; BUCKS, D.A. Trickle irrigation for crop production: design, operation and management. Amsterdam: Elsevier, 1986. p. 93-141. 